\title{
Appropriate and inappropriate vitamin supplementation in children
}

\author{
Lucia Martini $^{1}$, Luca Pecoraro ${ }^{1} *$ (D), Chiara Salvottini ${ }^{1}$, Giorgio Piacentini ${ }^{1}$, Richard Atkinson ${ }^{2}$ and \\ Angelo Pietrobelli ${ }^{1,3}$ \\ ${ }^{1}$ Department of Surgical Sciences, Dentistry, Gynecology and Pediatrics, Pediatric Clinic, University of Verona, Verona, Italy \\ ${ }^{2}$ Department of Internal Medicine, Virginia Commonwealth University, Richmond, VA, USA \\ ${ }^{3}$ Pennington Biomedical Research Center, Baton Rouge, LA, USA
}

(Received 11 December 2019 - Final revision received 26 April 2020 - Accepted 28 April 2020)

Journal of Nutritional Science (2020), vol. 9, e20, page 1 of 8

doi:10.1017/jns.2020.12

\section{Abstract}

The vitamin status of a child depends on many factors and most of the clinical studies do not take into account the different access to adequate nutrition of children coming from different countries and the consequent major differences in micronutrients or vitamin deficits between low-income and high-income countries. Vitamin supplements are included in the general field of dietary supplements. There is a large amount of not always factual material concerning vitamin supplements, and this may sometimes create confusion in clinicians and patients. Inadequate information may lead to the risk of attributing beneficial properties leading to their over-use or misuse in the paediatric field. Vitamin supplementation is indicated in all those conditions in which a vitamin deficiency is found, either because of a reduced intake due to reduced availability of certain foods, restrictive diets or inadequate absorption. The lack of guidelines in these fields may lead paediatricians to an improper use of vitamins, both in terms of excessive use or inadequate use. This is due to the fact that vitamin supplementation is often intended as a therapy of support rather than an essential therapeutic tool able to modify disease prognosis. In fact, various vitamins and their derivatives have therapeutic potential in the prevention and treatment of many diseases, especially in emerging conditions of paediatric age such as type 2 diabetes and the metabolic syndrome. The aim of the present article is to analyse the state of the art and consider new perspectives on the role of vitamin supplements in children.

\section{Key words: Vitamin A: Vitamin D: Vitamin E: Vitamin B: Folic acid: Vitamin C: Children}

Vitamin supplements are included in the general field of dietary supplements, meaning specifically 'food products added to the normal diet constituting a source of nutritional substances, like vitamins and minerals, or substances with a physiological or nutritional effect, like amino acids, essential fatty acids, fibres or vegetable extracts in pre-dosed forms ${ }^{(1)}$. There is a large amount of available material concerning vitamin supplements, and this may sometimes create confusion for both clinicians and patients. Inadequate information may lead to the risk of attributing beneficial properties and overlooking the side effects of these supplements, leading to their over-use in the paediatric field ${ }^{(2)}$. Continuous research in this field is very important in order to properly use these products in children. The use of vitamin supplements should be based on evidence-based medicine, with the awareness that the best source of vitamins is indeed a balanced diet, associated with a healthy lifestyle, particularly during growth ${ }^{(3)}$. It is difficult to compare clinical studies that involve different populations. Moreover, the vitamin status of a child depends on many factors and most of the clinical studies do not mention the differences in access to adequate nutrition of children coming from different countries. There can be major differences in micronutrients or vitamin deficits between low-income and high-income countries. However, a closer look at Europe reveals that, even in a resource-rich society with free access to any type of food, it may be difficult for some to reach an

Abbreviation: RR, risk ratio.

* Corresponding author: Luca Pecoraro, email lucapecoraro88@gmail.com 
adequate vitamin intake, especially for vitamins $\mathrm{D}$ and $\mathrm{E}$ and iodine ${ }^{(4)}$. Vitamin supplementation is recommended in conditions of nutritional deficiencies, such as in malabsorption syndromes, unusual diets or inadequate vitamin intake. The aim of the present review is to analyse the state of the art and consider new perspectives on the role of vitamin supplements in children.

\section{Material and methods}

The authors performed a systematic literature search through the Cochrane Library and Medline/PubMed databases. We selected original studies that were likely to evaluate new evidence regarding vitamin supplementation, both for lipidsoluble (vitamin $\mathrm{E}$, vitamin $\mathrm{A}$, vitamin $\mathrm{D}$ ) and water-soluble (vitamin $\mathrm{C}$, folic acid, vitamin $\mathrm{B}_{12}$ ) vitamins. This research was conducted in December 2019 and seventy-two articles were found. We decided not to include vitamin $\mathrm{K}$ in our research, given the confirmed and validated role in the prevention of neonatal haemorrhagic syndrome ${ }^{(5)}$. As far as recommended dietary allowances are concerned, we referred to the Italian levels of nutrient intake (LARN) ${ }^{(6)}$.

\section{Vitamin E}

Vitamin $\mathrm{E}$ includes a group of lipid-soluble compounds (i.e. tocopherols and tocotrienols), with $\alpha$-tocopherol being the most relevant. The most important dietary sources of vitamin $\mathrm{E}$ are vegetable oils, cereals and some types of nuts. Vitamin $\mathrm{E}$ is an important antioxidant agent that also has antimicrobic action.

The recommended dietary allowance of vitamin $\mathrm{E}$ is between 4 and $13 \mathrm{mg} / \mathrm{d}$, depending on age ${ }^{(6)}$.

Vitamin $\mathrm{E}$ has no relevant toxicity at high doses: it can cause muscle weakness, fatigue, nausea and diarrhoea. The most significant one, that may occur with very high doses (>1000 mg/ d), is bleeding ${ }^{(7)}$. Vitamin E deficiency is found in children affected by reduced gastrointestinal absorption, lipid malabsorption, specific congenital disorders in which absorption and storage of vitamin $\mathrm{E}$ in the liver are impaired ${ }^{(8)}$. Clinical signs of vitamin $\mathrm{E}$ deficiency are represented by haemolytic anaemia, peripheral neuropathy, retinopathy, ataxia, myopathy and impaired response to infectious stimuli. Vitamin E supplementation in patients with the above-mentioned signs is mandatory, even if the amount of the real need and the long-term effects are not yet clear.

Vitamin E supplementation also plays a role in premature infants. As identified by a Cochrane review, vitamin $\mathrm{E}$ reduces the risk of intraventricular haemorrhage and retinopathy of prematurity in premature babies, except in those who are at major risk such as very-low-birth-weight newborns, in whom vitamin $\mathrm{E}$ supplementation could increase the risk of sepsis. Evidence does not support the routine use of vitamin E supplementation by the intravenous route at high doses ${ }^{(9)}$.

Vitamin E seems to have an antioxidant role, helping in preventing chronic diseases in adult patients (i.e. CVD, malignancies), but no evidence has been found so far in the paediatric population ${ }^{(10-12)}$. Goldenstein et al. ${ }^{(13)}$ have shown that vitamin
E was able to reduce cardiovascular risk in a subgroup of diabetic patients carrying a specific genotype ${ }^{(13)}$. Moreover, in recent years, a possible role for vitamin $\mathrm{E}$ in the treatment of non-alcoholic steato-hepatitis has been emerging. A recent meta-analysis has demonstrated that vitamin $\mathrm{E}$ administration was able to improve not only laboratory parameters (i.e. liver enzymes) but also histological markers in steatohepatitis ${ }^{(14)}$. However, according to El Hadi et al. ${ }^{(15)}$, further studies are necessary to confirm these findings and to evaluate possible long-term side effects ${ }^{(15)}$. Vitamin $\mathrm{E}$ is also involved in immune function, in the regulation of some signal transduction pathways by modulating gene expression inducing antimicrobial activity ${ }^{(16)}$, and in endothelial homeostasis. Numerous studies have evaluated its role in diseases characterised by haemolysis: in patients affected by glucose-6-phosphate-dehydrogenase deficiency and thalassaemia. Vitamin E supplementation was not able to reduce haemolytic episodes ${ }^{(17)}$. However, in patients with $\beta$-thalassaemia, vitamin $\mathrm{E}$ seemed to reduce oxidative stress in target organs ${ }^{(18)}$.

Moreover, a recent study has shown an improvement in laboratory and clinical parameters after vitamin E supplementation in patients with dengue haemorragic fever. In fact, vita$\mathrm{min} \mathrm{E}$ at high doses (200-400 $\mathrm{mg}$ by mouth, age-adjusted) seems to significantly accelerate the increase in platelet number $(P<0.05)$, therefore reducing the risk of haemorrhage ${ }^{(19)}$.

\section{Vitamin A}

Vitamin A is the name of a group of fat-soluble retinoids, including retinol, retinal and retinyl esters, and can be found in foods of animal origin or in many types of fruits and vegetables containing carotenoids that are vitamin A precursors. The most important vitamin A metabolite is retinoic acid, that, through its intranuclear receptor, modulates many signal transduction pathways. Vitamin A is essential for adequate vision, to support cellular growth and differentiation and signalling, to maintain muscular integrity, and for immunological purposes. Recommended dietary allowances in the paediatric population are from 200 to $500 \mu \mathrm{g} / \mathrm{d}$, depending on age ${ }^{(())}$.

Acute vitamin A toxicity can cause nausea and vomiting. Chronic toxicity can cause changes in skin, hair and nails; abnormal liver test results; and birth defects in fetuses. Both types usually can cause headache and intracranial hypertension. Unless birth defects are present, adjusting the dose almost always leads to complete recovery ${ }^{(20)}$.

Vitamin A deficiency is rare in high-income countries, while it is quite widespread in developing countries, especially in children and pregnant women. Vitamin A deficiency represents an important cause of morbidity and mortality in infectious diseases, especially in cases of diarrhoea or measles, and in visual problems, affecting primarily nocturnal vision (i.e. xerophthalmia). Lack of vitamin A remains one of the leading causes of paediatric blindness in developing countries.

The role of vitamin A in the immune system is still debated. Multiple studies have demonstrated that vitamin A deficiency is associated with an increased incidence of infectious diseases and a consequent increased morbidity and mortality. The WHO recommends vitamin A supplementation in all patients 
between 6 months and 5 years who are at risk of vitamin A deficiency (in all developing countries). This recommendation is based on the evidence that vitamin A supplementation determines an overall reduction in mortality (risk ratio (RR) $0.88 ; 95 \%$ CI $0.83,0.93)$, a reduction in diarrhoea incidence (RR $0.88 ; 95 \%$ CI $0.79,0.98)$ and a reduction in measlesrelated morbidity ${ }^{(21)}$. In developed countries, where vitamin A deficiency is not frequent, its supplementation is not indicated $^{(22)}$. Specifically, vitamin A supplementation did not show any positive effect on the reduction of morbidity due to diarrhoea, according to studies performed on toddlers and preschool children ${ }^{(23)}$. In case of measles, the WHO recommends a high oral intake of vitamin A (30 mg) for $2 \mathrm{~d}$ in patients younger than 2 years old in those countries in which there is high risk of vitamin A deficiency. Kawasaki et al. ${ }^{(24)}$ and Yong et al. ${ }^{(25)}$ have shown a reduction in morbidity not associated with side effects, with the administration of a dose of vitamin A to Japanese children with measles, suggesting a potential beneficial role also in countries with adequate vitamin $\mathrm{A}$ intakes ${ }^{(24,25)}$.

Preterm infants have low vitamin A levels at birth, so several studies have been conducted to check if an additional vitamin A supplement (administered intramuscularly) may reduce complications of prematurity. Vitamin A in preterm infants appears to have a small benefit in reducing the combined outcome of death or chronic lung disease (moderate-quality evidence). Although there is a statistical reduction in chronic lung disease, these findings have to be balanced against the lack of other proven benefits and the acceptability of the treatment ${ }^{(26)}$.

Given its role in cellular differentiation, many studies performed on adult patients have investigated a possible role of vitamin A in the reduction of cancer risk, but a clear relationship has not yet been shown ${ }^{(27)}$.

Vitamin A could have therapeutic potential in glycaemic control by means of all-trans-retinoic acid, a vitamin A derivative, which is able to suppress the insulin signalling pathway resulting in increased insulin sensitivity ${ }^{(28)}$.

In terms of immune function regulation, especially at the mucosal level, the role of vitamin A is still under investigation. The retinoic acid metabolite has an important role in favouring lymphocyte homing at the intestinal level and in the activation and differentiation of $\mathrm{T}$ lymphocytes. Recent studies, however, have also demonstrated an immune-modulating effect of this vitamin, so that researchers propose multiple roles for vitamin $\mathrm{A}$ in the immune system: activation, differentiation and modulation ${ }^{(29)}$.

\section{Vitamin D}

Vitamin D is a lipid-soluble vitamin produced in humans in the skin from endogenous cholesterol due to exposure to UVB rays and subsequent transformation into its active form after two hydroxylation reactions in the liver and in the kidneys ${ }^{(30)}$.

Vitamin D can also be introduced orally in its active form and foods rich in this vitamin include fatty fishes, egg yolks, fatty cheeses and butter. Vitamin D is fundamental for adequate bone metabolism; it maintains $\mathrm{Ca}$ and phosphate metabolism by stimulating their absorption at the intestinal level, acting on osteoclasts, which reabsorb $\mathrm{Ca}$ and other minerals from the bone. At renal level it induces Ca reabsorption from the glomerular filtrate.

Recommended dietary allowances for vitamin D are between 10 and $15 \mu \mathrm{g} / \mathrm{d}$ ( $1 \mu \mathrm{g}$ of cholecalciferol corresponds to $40 \mathrm{IU}$ of vitamin $\mathrm{D})^{(6)}$.

Although rare, vitamin $\mathrm{D}$ excess (total intakes in the range of $1-14 \mathrm{mg} / \mathrm{kg}$ ) can cause toxicity that can present with severe hypercalcaemia, hypercalciuria or nephrocalcinosis. To prevent its toxicity, it is recommended to check serum 25-hydroxyvitamin D levels in infants and children who receive long-term vitamin $\mathrm{D}$ supplementation at or above the upper level of intake ${ }^{(31)}$. Vitamin D deficiency is very frequent: low levels of vitamin $\mathrm{D}$ are frequent in the case of malabsorption, liver and/or renal failure, in the case of co-administration of certain drugs (i.e. phenitoin, carbamazepine, steroids and anti-fungal drugs) and in cases of diseases requiring immobilisation. African Americans and Hispanics or patients with poor sun exposure, obese patients, subjects with granulomatous diseases and with hyperparathyroidism are at further risk of vitamin $\mathrm{D}$ deficiency.

Vitamin D supplementation is therefore indicated during the first year of life and in the above-mentioned patients at risk to prevent rickets and osteopenia both in Western and developing countries ${ }^{(32,33)}$. The most adequate vitamin $\mathrm{D}$ dosage is still debated and could be different for specific age groups. Further studies are also needed to clarify the issue related to daily $v$. monthly vitamin $\mathrm{D}$ administration ${ }^{(30)}$. In preterm infants, daily supplementation of vitamin $\mathrm{D}$ in higher doses (20-25 $\mu \mathrm{g}$ compared with $10 \mu \mathrm{g}$ ) appears to be better not only in development but also in immune function ${ }^{(34)}$. As vitamin $\mathrm{D}$ is a regulator of gene expression as well as cell proliferation and differentiation, various cross-sectional and longitudinal cohort studies have indicated a beneficial effect from vitamin $\mathrm{D}$ supplementation in the prevention of type 2 diabetes $^{(28)}$ and in the pathogenic process of type 1 diabetes ${ }^{(35)}$.

Vitamin D has an immunomodulatory effect both for innate and adaptive immunity.

A Cochrane review did not show a clear influence of vitamin D on overall mortality (RR 1.43; $95 \%$, CI $0.54,3.74$ ) and on the reduction of respiratory infections in patients younger than 5 years old ${ }^{(36)}$. Several studies have focused on the role of vitamin D in the course of pneumonia. Even in this case evidence is not very clear, suggesting a possible usefulness of supplementation, but without significant differences among the analysed groups ${ }^{(37)}$. Vitamin D (at normal dosage) plays a role in the prevention of acute otitis media, but not in its complications $(P=0.03)^{(38)}$. On the other hand, some studies have also investigated the role of vitamin $\mathrm{D}$ in the modulation of immune response. Adequate levels of vitamin $\mathrm{D}$ in humans seem to reduce the risk of developing conditions such as multiple sclerosis, idiopathic juvenile arthritis and, in those already affected, it seems to reduce the risk of disease activation or relapse. Adequate vitamin D levels in patients with Crohn's disease or systemic lupus erythematosus are associated with reduced severity of the disease per se. Despite these promising 
results, further trials will be necessary to confirm the potential role of vitamin $\mathrm{D}$ in preventing autoimmune diseases and in improving their natural evolution ${ }^{(39)}$. Vitamin $\mathrm{D}$ seems to be protective for pulmonary function in asthmatic patients. Studies conducted so far have demonstrated reduced levels of vitamin $\mathrm{D}$ in patients with asthma, but the correlation between vitamin $\mathrm{D}$ levels and pulmonary function is still controversial $^{(40)}$.

\section{Vitamin C}

Vitamin C is a water-soluble vitamin that is found in the human body in its reduced form, ascorbic acid. Fruits and vegetables represent the major source of vitamin C. Vitamin $\mathrm{C}$ is essential for collagen synthesis, particularly in the hydroxylation of the amino acids proline and lysine, and therefore it is important for the stability of connective tissue. Vitamin C is also involved in many enzymic reactions, in the modulation of functions of the central nervous system, and it also has an antioxidant role by neutralising reactive oxygen species ${ }^{(41)}$.

Recommended dietary allowances for vitamin $\mathrm{C}$ are between 35 and $75 \mathrm{mg} / \mathrm{d}$ depending on age ${ }^{(6)}$.

Vitamin C deficiency, or scurvy, is a rare entity nowadays, but it is still present in developing countries ${ }^{(42)}$. Scurvy clinical findings are mostly linked to the reduced production of collagen with an increased capillary fragility with cutaneous and gingival haemorrhages and musculoskeletal pain. Vitamin C deficiency is more frequent in Western countries in the context of restrictive diets in subjects with autism or neurological diseases, reduced absorption due to gastrointestinal disorders, and in renal conditions (chronic renal failure and dialysis).

As far as respiratory diseases are concerned, vitamin C supplementation was not shown to be beneficial in the case of upper airways inflammation, because it did not influence the severity or the length of the disease ${ }^{(43)}$. However, vitamin C supplementation seems to be useful in the case of recurrent respiratory infections. Garaiova et al. ${ }^{(44)}$ have shown that administration of vitamin $C$ and probiotics for 6 months is able to reduce the incidence $(P=0.002)$ and the length of infections $(P=0 \cdot 04)$, but this study takes into account the synergic action of both substances, so it is difficult to draw conclusions on vitamin $\mathrm{C}$ alone ${ }^{(44)}$. Vitamin $\mathrm{C}$ supplementation is able to reduce the duration and severity of community acquired pneumonia in adult patients (both at low and high doses up to $1.6 \mathrm{~g} / \mathrm{d}$ ), but no studies have been published so far on the paediatric population ${ }^{(45)}$. Despite the fact that a role for vitamin $\mathrm{C}$ in histamine and prostaglandin metabolism regulation in the lungs and bronchi has been demonstrated, with a possible bronchodilator effect, Milan et al. ${ }^{(46)}$ have not yet shown a rationale for the use of vitamin $C$ in allergic or exercise-induced asthma. Due to its neuromodulatory and antioxidant properties on the central nervous system, vitamin C seems to have a beneficial effect on depression in children, if utilised as a support therapy as an adjunct to standard therapy ${ }^{(47)}$. Moreover, studies have shown that vitamin C is able to reduce pain sensation in many pain disorders like postherpetic neuralgia, oncological pain and regional pain syndromes $^{(48,49)}$. In the field of haematology it is important to underline the ability of vitamin $\mathrm{C}$ to increase Fe absorption, converting $\mathrm{Fe}$ into its reduced form (i.e. $\mathrm{Fe}^{2+}$ ). Recent studies suggest its ability, if administrated with oral $\mathrm{Fe}$, to improve haematological parameters in patients with Fe-refractory Fe-deficiency anaemia $(250 \mathrm{mg} / \mathrm{d})$ for 10 weeks $^{(50)}$.

In dialysed patients or with chronic renal failure, supplementation of vitamin $\mathrm{C}$ was able to reduce blood levels of uric acid and to improve the lipid profile ${ }^{(51)}$. Vitamin $\mathrm{C}$ has shown some effects in obesity, reducing the proinflammatory state typical of this condition. However, further studies are necessary to establish the precise effect of vitamin C in obesity ${ }^{(52)}$. To conclude, a recent meta-analysis testing the effects of vitamin $C$ administration on glucose and insulin levels showed that vitamin $\mathrm{C}$ was able to significantly reduce glycaemia in patients with type 2 diabetes, especially with prolonged administration ${ }^{(53)}$.

\section{Vitamin $\mathrm{B}_{12}$}

Vitamin $\mathrm{B}_{12}$ is a water-soluble vitamin that can be naturally found in animal products. It is involved in DNA and $\mathrm{Hb}$ synthesis and is fundamental for proper neurological function, in order to maintain low levels of homocysteine to prevent damage at the endothelial level, and it acts as a cofactor in numerous metabolic pathways. Recommended intake for children varies between $0.7 \mu \mathrm{g} / \mathrm{d}$ in toddlers and $2 \mu \mathrm{g} / \mathrm{d}$ during adolescence $^{(6)}$. In order to be absorbed at the level of the terminal ileus, it must bind to intrinsic factor produced by the gastric mucosa. A frank vitamin $\mathrm{B}_{12}$ deficit, caused either by restrictive diets (i.e. vegan diet) or by absorption problems, clinically manifests itself with megaloblastic anaemia and neurological symptoms. Also, certain drugs can reduce vitamin $\mathrm{B}_{12}$ levels such as proton pump inhibitors, histamine-receptor antagonists and metformin ${ }^{(54)}$.

Vegan diets are becoming increasingly popular nowadays and, despite the fact that most International Societies for Nutritional Health do not recommend them during complementary feeding, a growing number of mothers are becoming vegan ${ }^{(55)}$. Vitamin $\mathrm{B}_{12}$ deficiency during pregnancy is associated with adverse events like pre-eclampsia, recurrent fetal losses, intra-uterine growth retardation, preterm delivery, low birth weight and neural tube defects ${ }^{(56)}$ and infants born to mothers with vitamin $\mathrm{B}_{12}$ deficiency during pregnancy have a high risk of developing growth failure, anorexia, involuntary movements, hyperpigmentation, abnormal electroencephalogram (EEG) and delays in speech development ${ }^{(57)}$. Furthermore, it has been demonstrated that vitamin $\mathrm{B}_{12}$ milk concentrations are strongly influenced by maternal serum vitamin $\mathrm{B}_{12}^{(58)}$. Therefore the recommended vitamin $\mathrm{B}_{12}$ supplementation for pregnant and lactating women should be as high as $250 \mu \mathrm{g} / \mathrm{week}$, while for children between 7 months and 6 years old should be around $1.4 \mu \mathrm{g} / \mathrm{d}^{(59)}$. Vitamin $B_{12}$ serum concentration is measured in pmol/l and it is considered depleted if below $120 \mathrm{pmol} / 1$ from birth to 6 month of age, below $165 \mathrm{pmol} / 1$ from 6 months to 12 month of age, and below $183 \mathrm{pmol} / \mathrm{l}$ from 12 months to 24 months of age ${ }^{(60)}$. Concerning laboratory tests, the vitamin $\mathrm{B}_{12}$ functional status can be evaluated by also measuring 
homocysteine and methylmalonic acid levels, which are typically increased in the case of vitamin $\mathrm{B}_{12}$ deficiency ${ }^{(61)}$.

Given its regulatory effect on homocysteine levels, vitamin $\mathrm{B}_{12}$ has an important cardiovascular role, reducing levels of homocysteine, but strong evidence is still lacking ${ }^{(62)}$. Low levels of vitamin $B_{12}$ are associated with obesity and insulin resistance, addressing a possible role for this vitamin in adipogenesis $^{(63,64)}$.

As far as neurological system functioning is concerned, studies conducted on the adult population have shown an association between vitamin $\mathrm{B}_{12}$ deficiency and an increased prevalence of dementia and cognitive decline, but were not able to demonstrate positive effects in case of supplementation ${ }^{(65)}$. Kvestad et al. ${ }^{(66)}$ have shown how vitamin $\mathrm{B}_{12}$ status during the first year of life is directly associated with neurocognitive development (social, visual-spatial and motor abilities) ${ }^{(66)}$. Due to the high prevalence of vitamin $B_{12}$ deficiency in children, associated with the risk of unfavourable neurocognitive outcomes, there is the need for additional studies that analyse the long-term effects of vitamin $B_{12}$ deficiency and the role of eventual supplementation ${ }^{(67)}$. Dobrozsi et al. ${ }^{(68)}$ reported four cases of children with vitamin $\mathrm{B}_{12}$ deficiency secondary to pernicious anaemia, a presumed transport protein abnormality, and a metabolic defect. All subjects demonstrated neurological compromise that improved after initiation of vitamin $\mathrm{B}_{12}$ therapy. The authors also underlined that therapy should be initiated promptly in this setting to prevent irreversible neuropathy ${ }^{(68)}$.

\section{Folic acid}

Folic acid is a water-soluble vitamin included in the B-vitamin group, also known as vitamin $\mathrm{B}_{9}$, and it is normally found in various vegetables. Folic acid has been recognised as essential in preventing congenital malformations, especially of the neural tube, that may originate during the early phases of embryogenesis.

Folic acid is also fundamental for nucleic acid synthesis, amino acid metabolism and appropriate cellular replication. Daily recommended intake is between 110 and $320 \mu \mathrm{g} / \mathrm{d}$ in breastfed infants and adolescents ${ }^{(6,69)}$. Inadequate diet is the origin of most cases of folic acid deficiency, but a reduced absorption or an increased need can occur with the administration of certain drugs (i.e. barbiturates, oestroprogestinics), high alcohol consumption, malabsorption disorders, and specific mutations in genes involved in folic acid metabolism. Given its importance for the synthesis of DNA and for cellular replication, folic acid is a recognised therapy in patients affected by sickle cell anaemia, due to the increased erythropoiesis and the need to increase folate reserves. Its effects on anaemia are still not clear, requiring further trials aimed at evaluating the effects of this supplementation on the morbidity associated with sickle-cell disease ${ }^{(69)}$.

Folic acid is an essential micronutrient for fetal development, growth and haemopoiesis; for preterm infants the European Society for Paediatric Gastroenterology, Hepatology and Nutrition (ESPGHAN) Committee on Nutrition 2010 ${ }^{(5)}$ recommended a minimum daily intake of 35 to $100 \mathrm{mg} / \mathrm{kg}$.
Table 1. Livelli di Assunzione di Riferimento di Nutrienti (LARN; Italian levels of nutrient intake) medium daily requirements*

\begin{tabular}{|c|c|c|c|c|c|}
\hline Age... & $\begin{array}{c}1-3 \\
\text { years }\end{array}$ & $\begin{array}{c}4-6 \\
\text { years }\end{array}$ & $\begin{array}{l}7-10 \\
\text { years }\end{array}$ & $\begin{array}{l}11-14 \\
\text { years }\end{array}$ & $\begin{array}{l}15-17 \\
\text { years }\end{array}$ \\
\hline Vitamin $A(\mu g)$ & 200 & 250 & 350 & 400 & $400-500$ \\
\hline Vitamin D $(\mu \mathrm{g})$ & 10 & 10 & 10 & 10 & 10 \\
\hline Vitamin C (mg) & 25 & 30 & 45 & $55-65$ & $60-75$ \\
\hline Vitamin $B_{12}(\mu \mathrm{g})$ & 0.7 & 0.9 & $1 \cdot 3$ & $1 \cdot 8$ & 2 \\
\hline Folic acid $(\mu \mathrm{g})$ & 110 & 140 & 210 & 290 & 320 \\
\hline
\end{tabular}

* Modified from SINU (Società Italiana di Nutrizione Umana) ${ }^{(6)}$. AR is the minimum requirement able to cover the needs in $50 \%$ of healthy subjects.

Preterm infants receiving parenteral nutrition with high folic acid content have no risk of folate deficiency during the first 2 months of age, but infants fed orally could be at risk for folate deficiency. Micronutrient support of maternal milk and the development of modern preterm formulas for preterm infants have decreased the need for folic acid supplementation, although the practice of folic acid supplementation remains commonplace, in the absence of a systematic review to support folate supplementation in preventing anaemia of prematurity $^{(70)}$.

Recently, researchers have also evaluated the association between folic acid and respiratory conditions, with or without atopy. An inverse relationship between folic acid levels and the level of allergic inflammation was observed (RR 2.2; $95 \%$ CI $1 \cdot 1,4 \cdot 6)$. Additional studies have also correlated folic acid levels with the severity of associated symptoms and with the number of relapses ${ }^{(71)}$.

WHO guidelines suggest that all women, from the moment they begin trying to conceive until 12 weeks of gestation, should take a folic acid supplement ( $400 \mu \mathrm{g}$ folic acid daily) to prevent neural tube defects. Questions remain about an improved nutritional surveillance in order to find the appropriate dose and supplementation scheme ${ }^{(72)}$.

\section{Conclusions}

Vitamin supplementation is indicated in all those conditions in which a vitamin deficiency is found, either because of a reduced intake due to scarce availability of certain foods, unbalanced or restrictive diets, or inadequate absorption. Even in children with Western-style diets it is important to search for risk factors that could influence vitamin status, as deficiencies are a common finding also in this population.

In Table 1 we have summarised the daily medium requirements of the vitamins.

The lack of guidelines in these fields may lead paediatricians to an improper use of vitamins, both in terms of excessive use or inadequate use. This is due to the fact that vitamin supplementation is often intended as a therapy of support rather than an essential therapeutic tool able to modify disease prognosis. In order to avoid misunderstanding, in Table 2 we have reported the different vitamins discussed in this article, their role, dosage and significance in studies where vitamin integration was used in the paediatric age. 
Table 2. Role, dosage and statistical significance of vitamin integration as an adjuvant in the treatment of diseases in children

\begin{tabular}{|c|c|c|c|c|c|c|}
\hline Vitamins & Pathology & $\begin{array}{l}\text { Features of the trial and } \\
\text { population }\end{array}$ & $\begin{array}{l}\text { Duration of } \\
\text { therapy }\end{array}$ & Dosage & $P$ & References \\
\hline Vitamin E & Dengue fever & $\begin{array}{l}\text { 127, Randomised } \\
\text { double-blind study, } \\
\text { placebo-controlled study, } \\
\text { Indian population }\end{array}$ & $7 d$ & $\begin{array}{l}200 \mathrm{mg} / \mathrm{d} \text { by mouth } \\
(5-9 \text { years }) \\
400 \mathrm{mg} / \mathrm{d} \text { by mouth } \\
(10-12 \text { years })\end{array}$ & $\begin{array}{l}\text { Clinical outcome, } \\
\quad P=0.023 \\
\text { Laboratory outcomes, } \\
P<0.05\end{array}$ & (19) \\
\hline Vitamin D & Acute otitis media & $\begin{array}{l}\text { 116, Randomised } \\
\text { double-blind study, } \\
\text { placebo-controlled study, } \\
\text { Italian population }\end{array}$ & 4 months & $25 \mu \mathrm{g} / \mathrm{d}$, oral & $P=0.03$ & (38) \\
\hline Vitamin A & Measles & $\begin{array}{l}n \text { 105, Randomised } \\
\text { double-blind study, } \\
\text { placebo-controlled study, } \\
\text { Japanese population }\end{array}$ & $1 \mathrm{~d}$ & $30 \mathrm{mg}$, oral & $P<0.05$ & (24) \\
\hline Vitamin C & Depression & $\begin{array}{l}n 12 \text {, Randomised } \\
\text { double-blind, } \\
\text { placebo-controlled pilot } \\
\text { study, Egyptian population }\end{array}$ & 6 weeks & $1000 \mathrm{~g} / \mathrm{d}$, oral & $P<0.0001$ & (47) \\
\hline Vitamin C & $\begin{array}{l}\text { Fe-deficiency anaemia, } \\
\text { Fe-refractory }\end{array}$ & $n 7$, Prospective study & 10 weeks & $\begin{array}{l}250 \mathrm{mg} / \mathrm{d} \text { plus } \mathrm{Fe} \\
\text { supplementation, } \\
\text { by mouth }\end{array}$ & $P=0.04$ & (50) \\
\hline Vitamin C & Chronic renal failure & $\begin{array}{l}n 60, \text { Randomised } \\
\text { single-blind, } \\
\text { placebo-controlled study, } \\
\text { Egyptian population }\end{array}$ & $\begin{array}{l}\text { Three times per } \\
\text { week for } 12 \\
\text { weeks }\end{array}$ & $\begin{array}{l}250 \mathrm{mg} / \mathrm{d} \\
\text { intravenous }\end{array}$ & $P<0.0001$ & (51) \\
\hline
\end{tabular}

Table 3. Fields of application of vitamin supplementation in which evidence is still lacking

\begin{tabular}{lll}
\hline Vitamin & Studies & References \\
\hline Vitamin E & R-Thalassaemia, non-alcoholic steatohepatitis & $(15,18)$ \\
Vitamin D & Respiratory infections, asthma, autoimmune disorders, type 1 and 2 diabetes & $(28,35,36,39,40)$ \\
Vitamin C & Pneumonia, allergic and exercise-induced asthma, acute and chronic respiratory infections, & $(44-46,48,49,52,53)$ \\
& pain control, obesity, type 2 diabetes & \\
Vitamin $B_{12}$ & Neurocognitive development, peripheral neuropathy, obesity and insulin resistance & $(63,66)$ \\
Folic acid & Sickle-cell disease, allergic inflammation & $(67,69,71)$ \\
\hline
\end{tabular}

In the literature, other possible applications of vitamin supplementation have been reported, such as vitamin $\mathrm{E}$ for patients with dengue fever ${ }^{(19)}$, vitamin A supplementation in measles $^{(24)}$, usefulness of vitamin $\mathrm{C}$ in disorders like depression, chronic renal failure and Fe-deficiency anaemia ${ }^{(47,51,50)}$, and vitamin $\mathrm{D}$ administration in patients with recurrent otitis $^{(38)}$.

In Table 3 we have summarised a few studies that, according to our knowledge, have shown very promising results $(15,18,28,35,36,39,40,44-46,48,49,52,53,63,66,67,69,71)$. However, further studies are needed to confirm the usefulness of various forms of vitamin administration and to analyse the long-term effects. The demonstrated evidence summarised in Tables 2 and 3 are only suggestions, which can help paediatricians in their daily practice. Guidelines on the need of vitamin supplementation in subjects in which a clear deficiency is not present are still lacking.

\section{Acknowledgements}

The authors declare that they did not receive any funding for this work.
A. P. and L. P. provided inputs to the structure of the manuscript; C. S. and L. M. wrote the first draft of the manuscript; A. P., R. A., L. P. and G. P. critically reviewed the manuscript for intellectual content. All authors read and approved the final edits and approved the manuscript.

The authors declare that they have no relevant conflicts of interest.

\section{References}

1. Pereira C, Barros L \& Ferreira ICFR (2017) Dietary supplements: foods, medicines, or both? A controversial designation with unspecific legislation. Curr Pharm Des 23, 2722-2730.

2. Rock CL (2007) Multivitamin-multimineral supplements: who uses them? Am J Clin Nutr 85, 277S-279S.

3. Bailey RL, Gahche JJ, Thomas PR, et al. (2013) Why US children use dietary supplements. Pediatr Res 74, 737-741.

4. Kaganov B, Caroli M, Mazur A, et al. (2015) Suboptimal micronutrient intake among children in Europe. Nutrients 7, 3524-3535.

5. Mihatsch WA, Braegger C, Bronsky J, et al. (2016) Prevention of vitamin $\mathrm{K}$ deficiency bleeding in newborn infants: a position paper by the ESPGHAN committee on nutrition. I Pediatr Gastroenterol Nutr 63, 123-129. 
6. SINU (Società Italiana di Nutrizione Umana) (2017) LARN: Livelli di Assunzione Italiana, Nutrienti ed energia per la popolazione (LARN: Italian Intake Levels, Nutrients and Energy for the Population). Rome: SICS Editore.

7. Klein EA, Thompson IMJ, Tangen CM, et al. (2011) Vitamin E and the risk of prostate cancer: the Selenium and Vitamin E Cancer Prevention Trial (SELECT). JAMA 306, 1549-1556.

8. Traber MG (2014) Vitamin E inadequacy in humans: causes and consequences. Adv Nutr 5, 503-514.

9. Brion LP, Bell EF \& Raghuveer TS (2003) Vitamin E supplementation for prevention of morbidity and mortality in preterm infants. Cocbrane Database Syst Rev, issue 4, CD003665.

10. Traber MG (2007) Heart disease and single-vitamin supplementation. Am J Clin Nutr 85, 293S-299S

11. Blumberg JB \& Frei B (2007) Why clinical trials of vitamin E and cardiovascular diseases may be fatally flawed. Commentary on "The relationship between dose of vitamin $\mathrm{E}$ and suppression of oxidative stress in humans". Free Radic Biol Med 43, 1374-1376.

12. Lee I-M, Cook NR, Gaziano JM, et al. (2005) Vitamin E in the primary prevention of cardiovascular disease and cancer: the Women's Health Study: a randomized controlled trial. JAMA 294, 56-65.

13. Goldenstein H, Levy NS, Lipener YT, et al. (2013) Patient selection and vitamin $\mathrm{E}$ treatment in diabetes mellitus. Expert Rev Cardiovasc Ther 11, 319-326.

14. Sato K, Gosho M, Yamamoto T, et al. (2015) Vitamin E has a beneficial effect on nonalcoholic fatty liver disease: a meta-analysis of randomized controlled trials. Nutrition 31, 923-930.

15. El Hadi H, Vettor R \& Rossato M (2018) Vitamin E as a treatment for nonalcoholic fatty liver disease: reality or myth? Antioxidants (Basel) 7, E12.

16. Pierpaoli E, Cirioni O, Barucca A, et al. (2011) Vitamin E supplementation in old mice induces antimicrobial activity and improves the efficacy of daptomycin in an animal model of wounds infected with methicillin-resistant Staphylococcus aureus. J Antimicrob Chemother 66, 2184-2185.

17. Johnson GJ, Vatassery GT, Finkel B, et al. (1983) High-dose vitamin $\mathrm{E}$ does not decrease the rate of chronic hemolysis in glucose-6phosphate dehydrogenase deficiency. N Engl J Med 308, 1014 1017.

18. Pfeifer WP, Degasperi GR, Almeida MT, et al. (2008) Vitamin E supplementation reduces oxidative stress in beta thalassaemia intermedia. Acta Haematol 120, 225-231.

19. Chathurangana PW, Samaranayake D, Gunalini Quienters V, et al. (2017) Effects of vitamin E supplementation on the clinical outcome of dengue fever and dengue haemorrhagic fever in children. Asian Pac J Trop Dis 7, 645-649.

20. Penniston KL \& Tanumihardjo SA (2006) The acute and chronic toxic effects of vitamin A. Am J Clin Nutr 83, 191-201.

21. Imdad A, Mayo-Wilson E, Herzer K, et al. (2017) Vitamin A supplementation for preventing morbidity and mortality in children from six months to five years of age. Cochrane Database Syst Rev, issue 3, CD008524.

22. Grotto I, Mimouni M, Gdalevich M, et al. (2003) Vitamin A supplementation and childhood morbidity from diarrhea and respiratory infections: a meta-analysis. J Pediatr 142, 297-304.

23. Yurdakok K, Ozmert E, Yalcin SS, et al. (2000) Vitamin A supplementation in acute diarrhea. J Pediatr Gastroenterol Nutr 31, 234-237.

24. Kawasaki Y, Hosoya M, Katayose M, et al. (1999) The efficacy of oral vitamin A supplementation for measles and respiratory syncytial virus (RSV) infection (article in Japanese). Kansenshogaku Zasshi 73, 104-109.

25. Yang HM, Mao M \& Wan C (2005) Vitamin A for treating measles in children. Cocbrane Database Syst Rev, issue 4, CD001479.

26. Darlow BA, Graham PJ \& Rojas-Reyes MX (2016) Vitamin A supplementation to prevent mortality and short- and long-term morbidity in very low birth weight infants. Cochrane Database Syst Rev, issue $8, \mathrm{CD} 000501$.

27. Alpha-Tocopherol Beta Carotene Cancer Prevention Study Group (1994) The effect of vitamin E and beta carotene on the incidence of lung cancer and other cancers in male smokers. $N$ Engl J Med 330, 1029-1035.

28. Dakshinamurti K (2015) Vitamins and their derivatives in the prevention and treatment of metabolic syndrome diseases (diabetes). Can J Physiol Pharmacol 93, 355-362.

29. Sirisinha $S$ (2015) The pleiotropic role of vitamin A in regulating mucosal immunity. Asian Pacific J Allergy Immunol 33, 71-89.

30. Dalle Carbonare L, Valenti MT, Del Forno F, et al. (2018) Vitamin $\mathrm{D}$ daily versus monthly administration: bone turnover and adipose tissue influences. Nutrients 10, E1934.

31. Vogiatzi MG, Jacobson-Dickman E \& DeBoer MD (2014) Vitamin $\mathrm{D}$ supplementation and risk of toxicity in pediatrics: a review of current literature. J Clin Endocrinol Metab 99, 1132-1141.

32. Braegger C, Campoy C, Colomb V, et al. (2013) Vitamin D in the healthy European paediatric population. J Pediatr Gastroenterol Nutr 56, 692-701.

33. Lerch C \& Meissner T. (2007) Interventions for the prevention of nutritional rickets in term born children. Cocbrane Database Syst Rev, issue 4, CD006164.

34. Yang Y, Li Z, Yan G, et al. (2018) Effect of different doses of vitamin D supplementation on preterm infants - an updated meta-analysis. J Matern Fetal Neonatal Med 31, 3065-3074.

35. Ziaei-Kajbaf T, Aminzadeh M, Fatahinezhad E, et al. (2018) Vitamin D status in diabetic children and adolescents. Diabetes Metab Syndr 12, 849-852.

36. Yakoob MY, Salam RA, Khan FR, et al. (2016) Vitamin D supplementation for preventing infections in children under five years of age. Cocbrane Database Syst Rev, issue 11, CD008824.

37. Das RR, Singh M \& Naik SS (2018) Vitamin D as an adjunct to antibiotics for the treatment of acute childhood pneumonia. Cocbrane Database Syst Rev, issue 7, CD011597.

38. Marchisio P, Consonni D, Baggi E, et al. (2013) Vitamin D supplementation reduces the risk of acute otitis media in otitis-prone children. Pediatr Infect Dis J 32, 1055-1060.

39. Yang C-Y, Leung PSC, Adamopoulos IE, et al. (2013) The implication of vitamin $\mathrm{D}$ and autoimmunity: a comprehensive review. Clin Rev Allergy Immunol 45, 217-226.

40. Jat KR \& Khairwa A (2017) Vitamin D and asthma in children: a systematic review and meta-analysis of observational studies. Lung India 34, 355-363.

41. Pecoraro L, Martini L, Antoniazzi F, et al. (2018) Vitamin C: should daily administration keep the paediatrician away? Int J Food Sci Nutr 70, 513-517.

42. Velandia B, Centor RM, McConnell V, et al. (2008) Scurvy is still present in developed countries. J Gen Intern Med 23, 1281-1284.

43. Hemilä H \& Chalker E (2013) Vitamin C for preventing and treating the common cold. Cochrane Database Syst Rev, issue 1, CD000980.

44. Garaiova I, Muchová J, Nagyová Z, et al. (2014) Probiotics and vitamin $C$ for the prevention of respiratory tract infections in children attending preschool: a randomised controlled pilot study. Eur J Clin Nutr 69, 373.

45. Hemilä H (2017) Vitamin C and infections. Nutrients 9, E339.

46. Milan SJ, Hart A \& Wilkinson M (2013) Vitamin C for asthma and exercise-induced bronchoconstriction. Cochrane Database Syst Rev, issue 10, CD010391.

47. Amr M, El-Mogy A, Shams T, et al. (2013) Efficacy of vitamin C as an adjunct to fluoxetine therapy in pediatric major depressive disorder: a randomized, double-blind, placebo-controlled pilot study. Nutr J 12, 31

48. Carr AC \& McCall C (2017) The role of vitamin C in the treatment of pain: new insights. $J$ Transl Med 15, 77 .

49. Aim F, Klouche S, Frison A, et al. (2017) Efficacy of vitamin C in preventing complex regional pain syndrome after wrist fracture: a systematic review and meta-analysis. Orthop Traumatol Surg Res 103, 465-470.

50. Sourabh S, Bhatia P \& Jain R (2019) Favourable improvement in haematological parameters in response to oral iron and vitamin $\mathrm{C}$ combination in children with iron refractory iron deficiency anemia (IRIDA) phenotype. Blood Cells Mol Dis 75, 26-29. 
51. El Mashad GM, El Sayed HM \& Nosair NA (2016) Effect of vitamin $C$ supplementation on lipid profile, serum uric acid, and ascorbic acid in children on hemodialysis. Saudi J Kidney Dis Transpl 27, 1148-1154.

52. Garcia OP, Ronquillo D, del Carmen Caamano M, et al. (2013) Zinc, iron and vitamins $\mathrm{A}, \mathrm{C}$ and e are associated with obesity, inflammation, lipid profile and insulin resistance in Mexican schoolaged children. Nutrients 5, 5012-5030.

53. Ashor AW, Werner AD, Lara J, et al. (2017) Effects of vitamin C supplementation on glycaemic control: a systematic review and meta-analysis of randomised controlled trials. Eur J Clin Nutr 71, 1371-1380.

54. Chapman LE, Darling AL \& Brown JE (2016) Association between metformin and vitamin $\mathrm{B}_{12}$ deficiency in patients with type 2 diabetes: a systematic review and meta-analysis. Diabetes Metab 42, 316-327.

55. Fewtrell M, Bronsky J, Campoy C, et al. (2017) Complementary feeding: a position paper by the European Society for Paediatric Gastroenterology, Hepatology, and Nutrition (ESPGHAN) Committee on Nutrition. J Pediatr Gastroenterol Nutr 64, 119-132.

56. Villalpando $S$ (2008) Effects of folate and vitamin $B_{12}$ deficiencies during pregnancy on fetal, infant, and child development. Food Nutr Bull 29, Suppl. 2, S112-S115.

57. Bailey HD, Miller M, Langridge A, et al. (2012) Maternal dietary intake of folate and vitamins $\mathrm{B}_{6}$ and $\mathrm{B}_{12}$ during pregnancy and the risk of childhood acute lymphoblastic leukemia. Nutr Cancer 64, 1122-1130.

58. Specker BL, Black A, Allen L, et al. (1990) Vitamin B-12: low milk concentrations are related to low serum concentrations in vegetarian women and to methylmalonic aciduria in their infants. $A m \mathrm{~J}$ Clin Nutr 52, 1073-1076.

59. Pawlak R (2017) To vegan or not to vegan when pregnant, lactating or feeding young children. Eur J Clin Nutr 71, 1259-1262.

60. Allen LH, Miller JW, de Groot L, et al. (2018) Biomarkers of Nutrition for Development (BOND): vitamin B-12 review. I Nutr 148, Suppl. 4, 1995S-2027S.
61. Green R, Allen LH, Bjorke-Monsen A-L, et al. (2017) Vitamin $B_{12}$ deficiency. Nat Rev Dis Primers 3, 17040.

62. Lichtenstein AH, Appel LJ, Brands M, et al. (2006) Diet and lifestyle recommendations revision 2006: a scientific statement from the American Heart Association Nutrition Committee. Circulation 114, 82-96.

63. Ho M, Halim JH, Gow ML, et al. (2014) Vitamin $B_{12}$ in obese adolescents with clinical features of insulin resistance. Nutrients $\mathbf{6}$, $5611-5618$.

64. Iglesia I, Gonzalez-Gross M, Huybrechts I, et al. (2017) Associations between insulin resistance and three B-vitamins in European adolescents: the HELENA study. Nutr Hosp 34, 568-577.

65. Eussen SJ, de Groot LC, Joosten LW, et al. (2006) Effect of oral vitamin B-12 with or without folic acid on cognitive function in older people with mild vitamin B-12 deficiency: a randomized, placebo-controlled trial. Am J Clin Nutr 84, 361-370.

66. Kvestad I, Hysing M, Shrestha M, et al. (2017) Vitamin B-12 status in infancy is positively associated with development and cognitive functioning 5 y later in Nepalese children. Am J Clin Nutr 105, 1122-1131.

67. Venkatramanan S, Armata IE, Strupp BJ, et al. (2016) Vitamin B-12 and cognition in children. Adv Nutr 7, 879-888.

68. Dobrozsi S, Flood VH, Panepinto J, et al. (2014) Vitamin B12 deficiency: the great masquerader. Pediatr Blood Cancer 61, 753-755.

69. Dixit R, Nettem S, Madan SS, et al. (2018) Folate supplementation in people with sickle cell disease. Cochrane Database Syst Rev, issue 2, CD011130.

70. Oncel MY, Calisici E, Ozdemir R, et al. (2014) Is folic acid supplementation really necessary in preterm infants $\leq 32$ weeks of gestation? J Pediatr Gastroenterol Nutr 58, 188-192.

71. Blatter J, Brehm JM, Sordillo J, et al. (2016) Folate deficiency, atopy, and severe asthma exacerbations in Puerto Rican children. Ann Am Thorac Soc 13, 223-230.

72. De-Regil LM, Fernandez-Gaxiola AC, Dowswell T, et al. (2010) Effects and safety of periconceptional folate supplementation for preventing birth defects. Cocbrane Database Syst Rev, issue 10, CD007950. 